RECEIVED

NOV 201998

OSTI

\title{
Sulfur Polymer Cement Stabilization of Elemental Mercury Mixed Waste
}

Dan Melamed, Mark Fuhrmann, Paul Kalb and Bhavesh Patel

April 1998

Prepared by:

Environmental \& Waste Technology Center

Department of Advanced Technology

Brookhaven National Laboratory

Prepared for:

U.S. Department of Energy

Contract No. DE-AC02-98CH10886

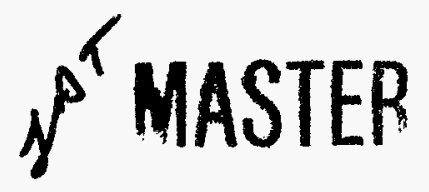




\section{DISCLAIMER}

This report was prepared as an account of work sponsored by an agency of the United States Government. Neither the United States Governmeat nor any agency thereof, nor any of their employees, makes any warranty, express or implied, or assumes any legal liability or responsibility for the accuracy, completeness, or usefulness of any information, apparatus, product, or process disclosed, or represents that its use would not infringe privately owned rights. Reference herein to any specific commercial product, process, or service by trade name, trademark, manufacturer, or otherwise does not necessarily constitute or imply its endorsement, recom. mendation, or favoring by the United States Government or any agency thereof. The views and opinions of authors expressed herein do not necessarily state or reflect those of the United States Government or any agency thereof. 


\section{DISCLAIMER}

Portions of this document may be illegible in electronic image products. Images are produced from the best available original document. 


\section{ABSTRACT}

Elemental mercury, contaminated with radionuclides, is a problem throughout the Department of Energy (DOE) complex. This report describes the development and testing of a process to immobilize elemental mercury, contaminated with radionuclides, in a form that is non-dispersible, will meet EPA leaching criteria, and has low mercury vapor pressure. In this stabilization and solidification process (patent pending) elemental mercury is mixed with an excess of powdered sulfur polymer cement (SPC) and additives in a vessel and heated to $\sim 35^{\circ} \mathrm{C}$, for several hours, until all of the mercury is converted into mercuric sulfide ( $\mathrm{HgS}$ ). Additional SPC is then added and the mixture raised to $135^{\circ} \mathrm{C}$, resulting in a homogeneous molten liquid which is poured into a suitable mold where it cools and solidifies. The final stabilized and solidified waste forms were characterized by powder X-ray diffraction, as well as tested for leaching behavior and mercury vapor pressure. During this study we have processed the entire inventory of mixed mercury waste stored at Brookhaven National Laboratory (BNL). 
. 


\section{TABLE OF CONTENTS}

ABSTRACT $\ldots \ldots \ldots \ldots \ldots \ldots \ldots \ldots \ldots \ldots \ldots \ldots \ldots \ldots \ldots \ldots$ iii

1.0 INTRODUCTION $\ldots \ldots \ldots \ldots \ldots \ldots \ldots \ldots \ldots \ldots \ldots \ldots \ldots \ldots$

2.0 MATERIALS AND METHODS $\ldots \ldots \ldots \ldots \ldots \ldots \ldots \ldots \ldots$

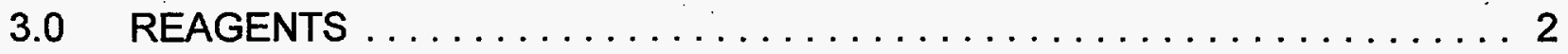

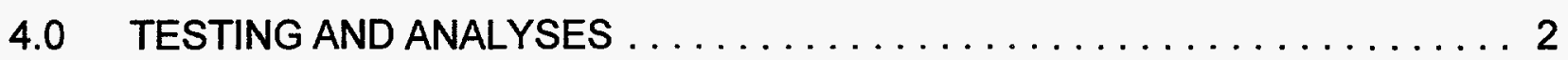

4.1 Process Development . . . . . . . . . . . . . . . . . 3

5.0 WASTE FORM PERFORMANCE $\ldots \ldots \ldots \ldots \ldots \ldots \ldots \ldots \ldots \ldots \ldots$

5.1 X-ray Diffraction Studies of the Waste Forms . . . . . . . . . . . . . . 7

5.2 Mercury Vapor . . . . . . . . . . . . . . . . . . 12

5.3 Processing BNL's Inventory of Mixed Mercury Waste . . . . . . . . . . 14

6.0 SUMMARY AND CONCLUSIONS $\ldots \ldots \ldots \ldots \ldots \ldots \ldots$

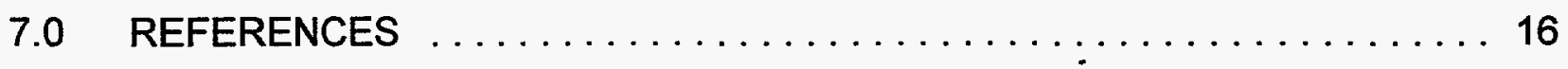





\section{LIST OF TABLES}

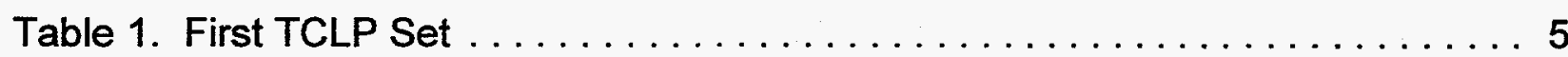

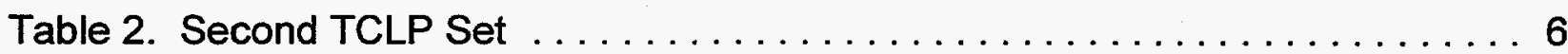

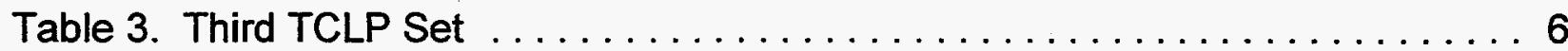

Table 4. Diffraction Data for SPC and Orthorhombic Sulfur $\ldots \ldots \ldots \ldots \ldots$

Table 5. Diffraction Data for the Black Waste Form in Figure $2 \ldots \ldots \ldots \ldots$

Table 6. X-Ray Diffraction Data for SPC-Hg-Cyanex 471x Waste Form, Cubic Mercuric Sulfide and Orthorhombic Sulfur . . . . . . . . . . . . 10

Table 7. X-Ray Diffraction Data for SPC-Hg- $\mathrm{Na}_{2} \mathrm{~S}$ Waste Form, Cubic Mercuric Sulfide and Orthorhombic Sulfur . . . . . . . . . . . . . 11

Table 8. Hg Vapor concentrations in Bottles Containing Various $\mathrm{Hg}$ Wastes . . . . 14

Table 9. BNL Inventory of Mixed Mercury Waste $\ldots \ldots \ldots \ldots \ldots \ldots \ldots$

\section{LIST OF FIGURES}

Figure 1. SPC Powder Diffraction Pattern $\ldots \ldots \ldots \ldots \ldots \ldots \ldots \ldots$

Figure 2. SPC and Mercury: Black Waste Form $\ldots \ldots \ldots \ldots \ldots \ldots$

Figure 3. SPC, Mercury and Cyanex 471x: Black Waste Form $\ldots \ldots \ldots \ldots \ldots$

Figure 4. SPC, Mercury and Sodium Sulfide: Red Waste Form ............ 10

Figure 5. Calibration plot of $\mathrm{Hg}$ vapor generated by reduction of aqueous $\mathrm{Hg}$ with Stannous Chloride. The vapor concentrations observed by the adaptation of the AA cold vapor method to vapor samples taken by syringe, gave a linear relationship

Figure 6. Concentration of $\mathrm{Hg}$ vapor as a function of time, in a bottle containing $\mathrm{Hg}$ processed in SPC. The vapor concentration decreases over a period of a week 
Mixed wastes, containing mercury as well as radionuclides, are a problem throughout the Department of Energy (DOE) complex. This highly variable type of waste includes radioactively contaminated elemental mercury as well as bulk materials, such as soils or debris, that contain dispersed mercury. Waste containing dispersed mercury can be treated by current technologies such as retorting and/or extraction, as well as by new processes being investigated. These separation methods will remove the mercury from the bulk waste; but, in the process, a secondary waste stream of concentrated mercury will be generated. Consequently, large volumes of elemental mercury-mixed waste will result; waste that must be treated for disposal.

Environmental Protection Agency (EPA) regulations (40CFR268.40) stipulate that mercury be "amalgamated" before disposal. As defined, this "amalgamation" requires that the mercury be combined with reagents such as copper, gold, or sulfur that result in a solid, non-volatile product. It should be noted that, according to EPA regulations 40 CFR 268.40, all processes where mercury is mixed with metals and sulfur are called amalgamation. However, combining mercury with sulfur results in mercuric sulfide, a new compound, not an amalgam or alloy, which is the result of mercury mixing with a metal. For the remainder of this paper we will refer to the process when mercury is combined with sulfur as mercuric sulfide formation. In order for the mixed waste mercury, treated according to EPA regulations 40 CFR 268.40 , to be disposed of properly, it must also comply with the Resource Conversion and Recovery Act (RCRA). This requires that the waste form pass the Toxicity Characteristic Leaching Procedure (TCLP). Therefore, any mercury contaminated with radioactive material, or mercury that at one point was in contact with radioactive material, has to be transformed into an amalgam or a sulfide that will pass the TCLP.

A study by Oak Ridge National Laboratory [1] found elemental mercury stabilized with sulfur to have better leaching properties and lower vapor pressures compared with other reagents. This sulfur treatment produces a chemically stable dry powder, but does not provide any additional barrier to leaching and is susceptible to mechanical dispersion of the radioactive material. A solution to the dispersibility of the mercuric sulfide involves using sulfur polymer cement (SPC). SPC is elemental sulfur modified with organic compounds which results in a new material with enhanced environmental stability. Many studies have shown that SPC can be highly effective at encapsulating toxic, low-level radioactive and mixed waste $[2,3,4,5]$. In this study we have examined the treatability of mercury and mercury-mixed waste using SPC, resulting in a monolithic waste form that complies with both RCRA and EPA protocols. During this study we have processed the entire inventory of mixed mercury waste at Brookhaven National Laboratory (BNL).

\subsection{MATERIALS AND METHODS}

Initial stabilization trials were conducted in either a 5-gallon steel or plastic drum attached to a paint shaker (5033 Series Red Devil Minneapolis, MN). Mercury, SPC and 
quartz cobbles (added to enhance agitation) were placed in a sealed vessel which was then purged with argon. The process was later refined to accomplish stabilization and solidification in one vessel, thereby improving efficiency and reducing health and safety risks associated with handling a dispersible mixed waste powder. In the one-pot stabilization and solidification process, the reaction vessel was changed to a 5-gallon heavy-gauge steel drum attached to the paint shaker with heating tape surrounding the vessel to heat the reaction mixtures. To monitor and control the temperature, a thermocouple was inserted into the vessel and connected to a digital PID controller. The controller, connected to the heating tape, allowing precise control of the reaction vessel's temperature and prevented any overheating. The vessel was equipped with openings that allow venting of gases from the heating of the sulfur polymer cement. The shaker is installed with the mixer end inside a walk-in fume hood, to allow any mercury or sulfur vapors to be safely dispersed. The lab-scale mixer was operated with a secondary containment pan to mitigate any potential leaks. centrifuge.

Centrifugation, performed to test for unreacted mercury was done on a Sorval RC-5

\subsection{REAGENTS}

Sulfur Polymer Cement was provided by Martin Resources (Odessa, TX). Initial studies used SPC that was ground in a ball mill containing quartz cobbles. The resulting powder was separated using a 60-mesh sieve. For larger scale studies, the Buffalo Steel Mill Company (Buffalo, NY) was contracted to grind the SPC to a fine powder. The resultant material was a fine powder that was $~ 60 \%$ finer than 60 mesh. When grinding the SPC the vender experienced a small dust explosion. In the future this operation should be conducted in an inert atmosphere to reduce dust explosion hazards.

Sodium sulfide nonahydrate $\left(\mathrm{Na}_{2} \mathrm{~S}-9 \mathrm{H}_{2} \mathrm{O}\right)$ was obtained from the Cooper Chemical Company (Long Valley, $\mathrm{NJ}$ ). This material was received as large crystals and had to be pulverized using a hammer or a mortar and pestle.

Triisobutyl phosphine sulfide, also known as Cyanex $471 \mathrm{x}$, was a provided by the Cytec corporation (Niagra Falls, ON).

\subsection{TESTING AND ANALYSES}

For this study, the Toxicity Characteristic Leaching Procedure (TCLP) was conducted using 50 grams of sample material, rather than the prescribed 100 grams, while maintaining the same relative reagent quantities required for a standard TCLP test [6]. This modified version of the TCLP is useful, reducing the volume of waste generated without compromising the assay. The filtered TCLP solution was analyzed using a Liberty 100 Inductively Coupled Plasma (ICP) Spectrometer or, for greater sensitivity, the mercury cold vapor method. This cold vapor analyses (EPA method 7470) were performed using 
a Perkin Elmer Model 4000 Atomic Absorption spectrometer with a Perkin Elmer Model MHS-10 Mercury/Hydride system. The required pre-tests dictated the use of TCLP solution I for all of the samples used in this study. TCLP specimens were fabricated as pellets (capable of passing through a $4.75 \mathrm{~mm}$ sieve) in Teflon molds.

Mercury vapor in the laboratory was tested using a commercial mercury vapor detector and Drager tubes, obtained from Sargent Welch (Philadelphia, PA). Mercury vapor measurements were also performed using a Model MV-2 Mercury Vapor Sniffer. Analyses of mercury vapor generated by the final waste forms were done by sealing small samples $(\sim 7 \mathrm{gm}$.) of the waste form in $250 \mathrm{ml}$ plastic bottles and letting the mercury vapors come to equilibrium at room temperature (at least 18 hours). A sample of $5 \mathrm{ml}$ was taken with a syringe from the headspace of these sample vials. The headspace sample was injected into a glass bottle, sealed with a septum. An argon stream carried any mercury vapor to the absorption cell of a Perkin Elmer Model MHS-10 Mercury/Hydride system where the vapor concentration was measured using the Perkin Elmer Model 4000 Atomic Absorption spectrometer. The amount of mercury vapor was calibrated using known quantities of a mercury standard generated in $250 \mathrm{ml}$ bottles using techniques identical to the mercury cold vapor method (EPA method 7470 ).

\subsection{Process Development}

Treating the mixed-waste mercury is a two-stage single vessel process. The first step is a reaction between mercury and powdered SPC (which is $95 \%$ elemental sulfur), forming mercuric sulfide.

$$
\mathrm{Hg}+\mathrm{S} \longrightarrow \mathrm{HgS}
$$

The second step involves adding more SPC and heating the mixture to a homogeneous melt and pouring the liquid material into a paint can where it cools into a monolithic waste form.

In the first step, equal masses of mercury and SPC are mixed in the reaction vessel. Equal amounts (by weight) of SPC and mercury assure nearly a sixfold molar excess of sulfur to mercury which facilitates a faster reaction of the mercury metal with sulfur. Although the ratio of mercury to SPC worked well, additional work is needed in order to optimize the reaction times, material costs and the performance of the final waste form. Prior to mixing, the reaction vessel was placed under an argon atmosphere to prevent the formation of mercuric oxide, a water soluble and highly leachable compound. The vessel was heated to $-35^{\circ} \mathrm{C}$ with agitation for 4 to 8 hours to accelerate the sulfide formation reaction. 
Sometimes mercury oxides or other soluble mercury salts exist in the metallic mercury or are formed while processing the metal compromising the waste forms performance. In those cases additives to the reaction mixture are added, to reduce the leaching of mercury salts from the resultant waste form. For this study two additives were examined: sodium sulfide and triisobutyl sulfide. Sodium sulfide has been successfully used as an additive to limit the leaching of heavy metal wastes encapsulated in SPC $[2,3,4,5]$. Triisobutyl phosphine sulfide, marketed under the trade name Cyanex $471 \mathrm{x}$, is a ligand with a strong affinity for mercury and has been successfully used to extract mercury from water [7].

To test the progress of the stabilization reaction, an aliquot $(\sim 10 \mathrm{gm}$.) of the crude reaction mixture was placed in a centrifuge tube and spun between 7,500 and $10,000 \mathrm{rpm}$ for one hour. When unreacted elemental mercury remained in the mixture, a visible layer of mercury formed on the surface of the tube. In one sample, where the amount of unreacted mercury was significant, it was separated and weighed: the isolated mercury was 0.75 grams and the remaining sample was 9.83 grams. Therefore, approximately $15 \%$ of the mercury was unreacted and isolated, i.e., the reaction was $85 \%$ completed. Although, this method is crude, it can be used to determine whether the reaction is up to $99 \%$ complete, judging from the quantity of unreacted mercury isolated.

A mild exotherm was observed when a mixture of SPC powder, mercury and either Cyanex $471 \mathrm{x}$ or sodium sulfide were mixed and warmed to $\sim 35^{\circ} \mathrm{C}$. The temperature of the reaction mixture would rise to $\sim 70^{\circ} \mathrm{C}$ for several hours, after which the reaction was complete. Although these additives were intended to improve leaching behavior of the resultant waste forms, they also decreased reaction times. This makes it possible to process a batch in eight hours compared with the sixteen-hour cycle required without the use of additives.

Once the mercury sulfide reaction was complete, the resultant material was melted and reformed into a monolith. To facilitate processing, extra SPC was added. For this study, the resultant waste form had a total waste loading of $33.3 \%$ mercury, by weight. Higher waste loadings may be possible through process optimization.

A final procedure was developed for use with the BNL inventory of radioactive contaminated mercury, after careful characterization of the immobilized and solidified mercury waste forms. The mercury mixed waste, and weighed quantities of Sulfur Polymer Cement and one additive $\left(\mathrm{Na}_{2} \mathrm{~S}-9 \mathrm{H}_{2} \mathrm{O}\right)$ were added to the reaction vessel. After all the materials were loaded, argon gas was then used to purge any air from the reaction vessel. The reaction mixture was then heated to $40^{\circ} \mathrm{C} \pm 5^{\circ}$, while mixing, for about 4 hours to allow the mercury and sulfur to react after additional SPC was added. The temperature was raised to $135^{\circ} \mathrm{C} \pm 5^{\circ}$ until the mixture melted. Molten sulfur polymer cement, loaded with mercuric sulfide and radionuclides, was then poured into paint cans and cooled to a solid for ultimate disposal. 
The main objectives of converting radioactively contaminated mercury metal into a monolithic mercuric sulfide are to reduce both the mercury vapor released into the atmosphere and mercury compounds leached out of these waste forms. Therefore, evolution of mercury vapor and the leaching behavior of these waste forms were the performance parameters measured for this study. For disposal in a landfill, a waste form must reach less than $200 \mathrm{ppb}$ of soluble mercury when subjected to a TCLP assay. We found that the leaching performance of these waste forms varied widely according to their process history. Our initial assay was to test the unprocessed mercury as a baseline, then the stabilized product of mercury and SPC and lastly the mercuric sulfide microencapsulated in SPC.

In the first TCLP set, shown in Table 1, the assays were performed on mercury metal and mercury stabilized with SPC powder. As shown in TCLP I, untreated mercury metal failed the assay, as expected. Note, mercury metal is not very soluble in acid solutions $(60 \mathrm{ppb})$ [8], a lower concentration than that found in the TCLP assay. Thus, there must be other mercury species solubilized during the assay, probably mercuric compounds formed by reactions with oxygen dissolved in the TCLP solution. For TCLP II and TCLP III two samples from a stabilization reaction were used. For the sample submitted for TCLP II, centrifugation showed that some unreacted mercury was present in the reaction mixture, while the sample submitted for TCLP III was free of unreacted mercury. Since both TCLP tests of the stabilized material showed no soluble mercury, although there is elemental mercury present in the sample for TCLP II, elemental sulfur must be reacting with soluble mercury compounds during the TCLP test. The use of an ICP spectrometer for mercury measurements is limited by its poor sensitivity $(\sim 100 \mathrm{ppb})$ which is very close to the TCLP threshold for that metal $(200 \mathrm{ppb})$. Therefore, for the remainder of this study, we used the cold vapor method (EPA method 7470), which is a much more sensitive mercury assay than ICP spectroscopy.

Table 1. First TCLP Set

\begin{tabular}{|l|l|l|}
\hline Assay Number & Material & TCLP Results, $[\mathrm{Hg}]^{*}$ \\
\hline TCLP I & metallic $\mathrm{Hg}$ & $2,640 \mathrm{ppb}$ [FAIL] \\
\hline TCLP II & $\mathrm{Hg}+$ SPC & none detected $(<100 \mathrm{ppb})$ [PASS] \\
\hline TCLP III & $\mathrm{Hg}+$ SPC & none detected $(<100 \mathrm{ppb})$ [PASS] \\
\hline
\end{tabular}

* The mercury concentrations for this test were measured using an ICP spectrometer.

In the next set of TCLP tests the mercury was stabilized with SPC, mixed with extra SPC, melted and molded into a monolithic waste form with $33.3 \%$ waste loading. These samples were hand mixed in a laboratory beaker that was heated on a hot plate. The 
molten material was molded into pellets, and submitted to the TCLP assay. Results of those tests are shown in Table 2. The first mercury-SPC waste form failed the TCLP test, which was surprising since that material was similar to the stabilized mercury tested in Table 1. This may be due to inhomogeneities resulting from poor mixing and/or the formation of soluble mercury oxide during the heating stage. However, those waste forms made using Cyanex $471 \mathrm{x}$ and sodium sulfide passed the TCLP test suggesting that additives can improve the waste forms' leaching behavior.

Table 2. Second TCLP Set

\begin{tabular}{|l|l|l|}
\hline Assay Number & Material & TCLP Results, [Hg] \\
\hline TCLP Ib & $\mathrm{Hg}+\mathrm{SPC}$ & $480 \mathrm{ppb}[\mathrm{FAlL}]$ \\
\hline TCLP Ilb & $\mathrm{Hg}+\mathrm{SPC}+\mathrm{Na}_{2} \mathrm{~S} \cdot 9 \mathrm{H}_{2} \mathrm{O}(3 \%)$ & $70 \mathrm{ppb}[\mathrm{PASS}]$ \\
\hline TCLP IIlb & $\mathrm{Hg}+\mathrm{SPC}+\mathrm{Cyanex} 471 \times(2 \%)$ & $120 \mathrm{ppb}[\mathrm{PASS}]$ \\
\hline
\end{tabular}

* The mercury concentrations for this test were measured using EPA method 7470 .

The performance of waste forms synthesized on a larger scale (5 $\mathrm{kg}$ of mercury), in an improved process conducted entirely in a single vessel was evaluated. The results from a final set of TCLP assays are shown in Table 3 . As seen in Tables 2 and 3 samples with no additive or with Cyanex 471 did not consistently result in acceptable levels of mercury in TCLP leachates. The combination of both sodium sulfide and Cyanex 471x passed TCLP easily but with no better performance than the sodium sulfide. The results show that the only waste forms that consistently perform well under the TCLP test are those made with sodium sulfide nonahydrate, which was chosen as the additive for additional formulations.

Table 3. Third TCLP Set

\begin{tabular}{|l|l|l|}
\hline Assay Number & Material & TCLP Results, [Hg] \\
\hline TCLP Ic & $\mathrm{Hg}+\mathrm{SPC}$ & Overrange $(>400 \mathrm{ppb})$ [FAIL] \\
\hline TCLP Ilc & $\mathrm{Hg}+\mathrm{SPC}$ & $20 \mathrm{ppb}$ [PASS] \\
\hline TCLP IIlc & $\mathrm{Hg}+\mathrm{SPC}+$ Cyanex $471 \times(3 \%)$ & $420 \mathrm{ppb}$ [FAlL] \\
\hline TCLP IVc & $\mathrm{Hg}+\mathrm{SPC}+\mathrm{Na}_{2} \mathrm{~S} \cdot 9 \mathrm{H}_{2} \mathrm{O}(3 \%)$ & $26 \mathrm{ppb}$ [PASS] \\
\hline TCLP VC & $\begin{array}{l}\mathrm{Hg}+\mathrm{SPC}+\mathrm{Na}_{2} \mathrm{~S} \cdot 9 \mathrm{H}_{2} \mathrm{O}(1.5 \%) \\
+ \text { Cyanex } 471 \times(1.5 \%)\end{array}$ & $64 \mathrm{ppb}$ [PASS] \\
\hline
\end{tabular}




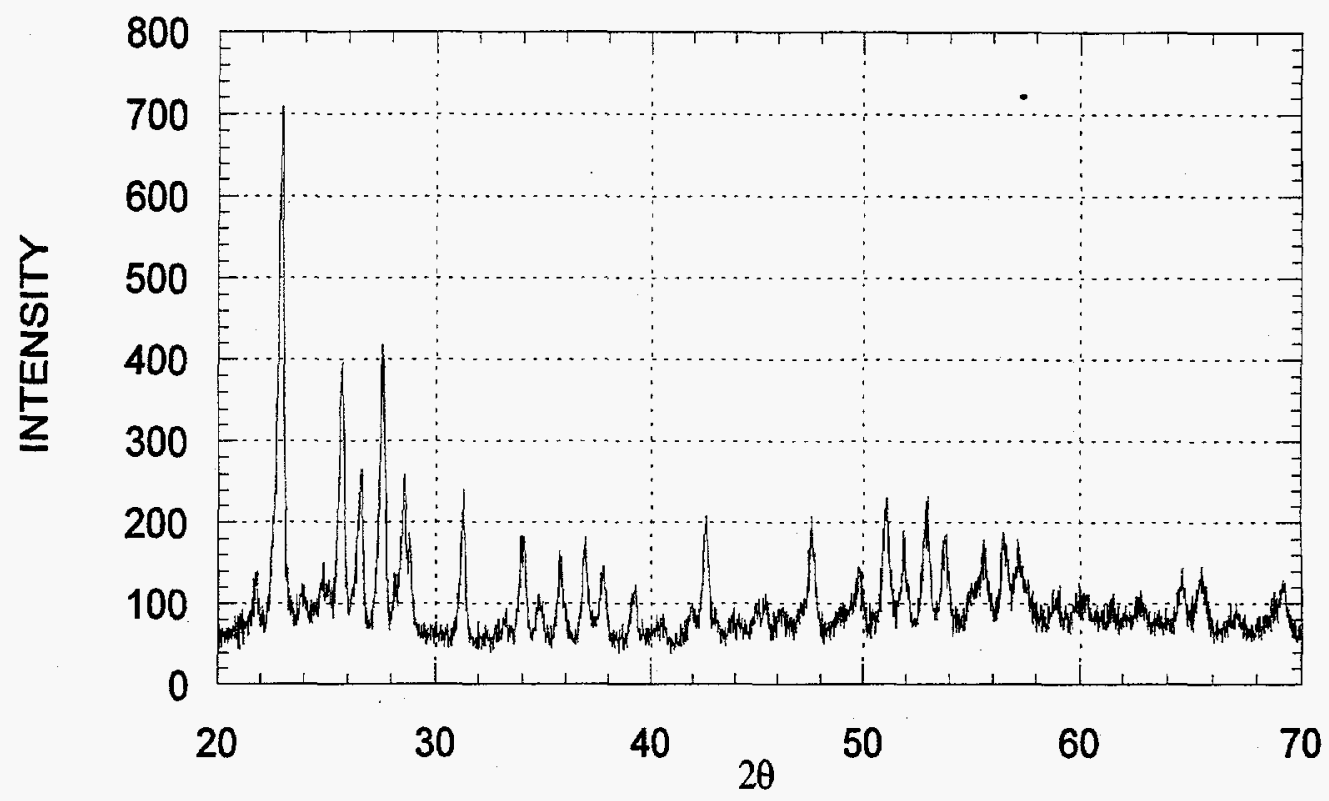

Figure 1. SPC Powder Diffraction Pattern

\subsection{X-ray Diffraction Studies of the Waste Forms}

The effect of additives to the performance of the mercury waste form is worth examining. When no additive or Cyanex $471 x$ was used the resultant waste form was a lustrous black. When sodium sulfide was used, the waste form produced was a dull orange color. This is not surprising since it is well known that mercuric sulfide has two stable forms, one, a cubic phase that is black, the other an orthorhombic phase that is red. $X$-ray powder diffraction was used to characterize the chemical species in the waste forms.

The X-ray powder diffraction pattern for SPC, which had been remelted, solidified and pulverized, is shown in Figure 1. The diffraction pattern corresponds well with the orthorhombic phase of elemental sulfur [9]. This is shown in Table 4, which compares the $d$-spacing and the relative intensity for the SPC sample with the literature values for the diffraction pattern of orthorhombic sulfur. This agrees well with a previous study that found SPC to be largely orthorhombic sulfur [10]. 
Table 4. Diffraction Data for SPC and Orthorhombic Sulfur

\begin{tabular}{|c|c|c|c|}
\hline \multicolumn{2}{|l|}{ SPC (this work) } & \multicolumn{2}{c|}{ Orthorhombic Sulfur } \\
\hline d-spacing & Intensity & d-spacing & Intensity \\
\hline 4.078 & 21 & 4.062 & 15 \\
\hline 3.877 & 100 & 3.859 & 100 \\
\hline 3.576 & 24 & 3.571 & 11 \\
\hline 3.463 & 58 & 3.450 & 42 \\
\hline 3.355 & 33 & 3.387 & 23 \\
\hline 3.234 & 66 & 3.220 & 50 \\
\hline
\end{tabular}

When the elemental mercury and the powdered SPC react they form a black powder. This material, when mixed with extra SPC, melted, mixed and cast results in a black waste form. The powder diffraction pattern from a crushed sample of that material is shown in Figure 2. The black material is easily identified as the cubic form of mercuric sulfide, also known as metacinnabar. The diffraction pattern, tabulated in Table 5, shows the waste form to be composed of metacinnabar [11] and sulfur [10].

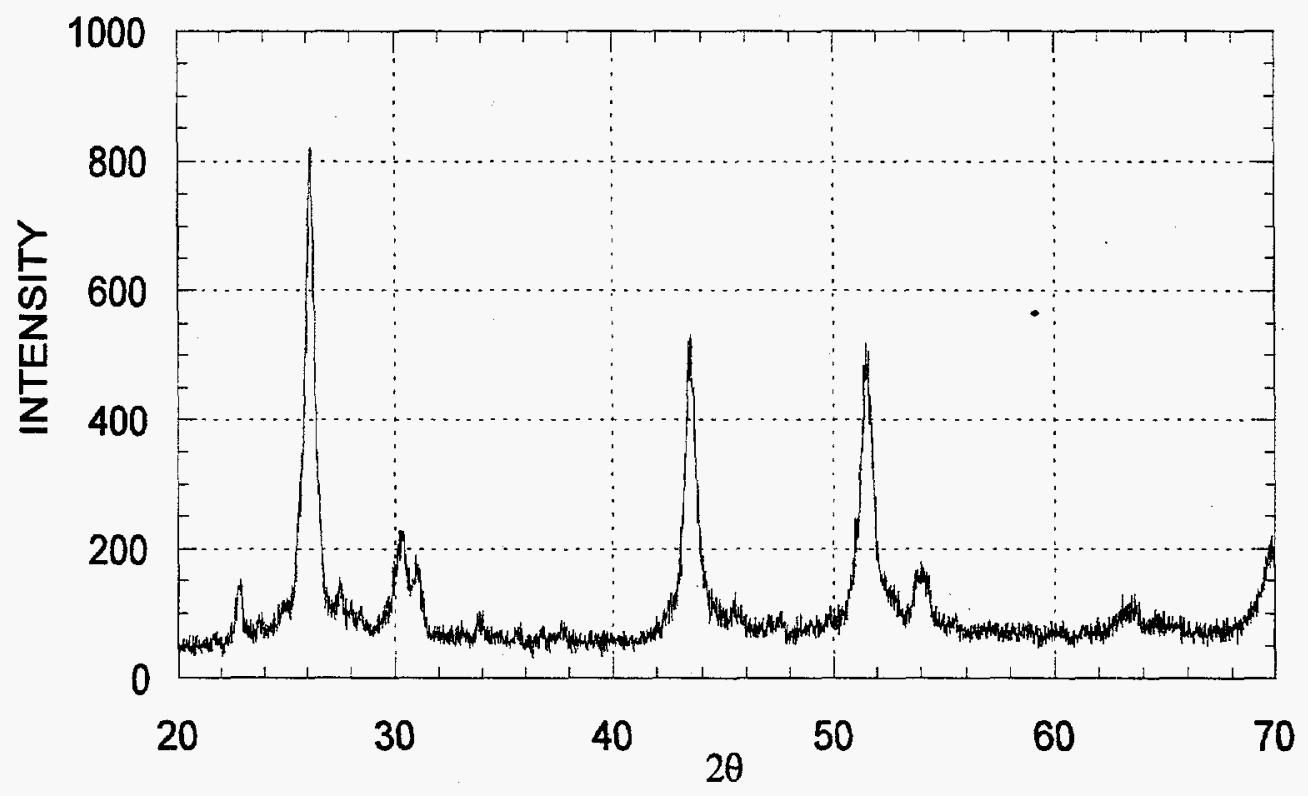

Figure 2. SPC and Mercury: Black Waste Form 
Table 5. Diffraction Data for the Black Waste Form in Figure 2

\begin{tabular}{|l|l|l|l|l|l|}
\hline \multicolumn{2}{|c|}{ Black Waste Form } & \multicolumn{2}{c|}{ Cubic Mercuric Sulfide } & \multicolumn{2}{c|}{ Orthorhombic Sulfur } \\
\hline d-spacing & Intensity & d-spacing & Intensity & d-spacing & Intensity \\
\hline 3.891 & 17 & & & 3.859 & 100 \\
\hline 3.401 & 100 & 3.378 & 100 & & \\
\hline 3.234 & 18 & & & 3.220 & 50 \\
\hline 2.949 & 28 & 2.926 & 34 & & \\
\hline 2.873 & 21 & & & 2.848 & 23 \\
\hline 2.078 & 64 & 2.068 & 57 & & \\
\hline 1.769 & 57 & 1.764 & 45 & & \\
\hline
\end{tabular}

When Cyanex $471 \mathrm{x}$ is added to the reaction mixture of mercury and powdered SPC, the final product is a lustrous black waste form. The powder diffraction pattern from a crushed sample of that material is shown in Figure 3 . As in the waste form prepared with no additive, this material is a mixture of metacinnabar and sulfur, as shown in Table 6.

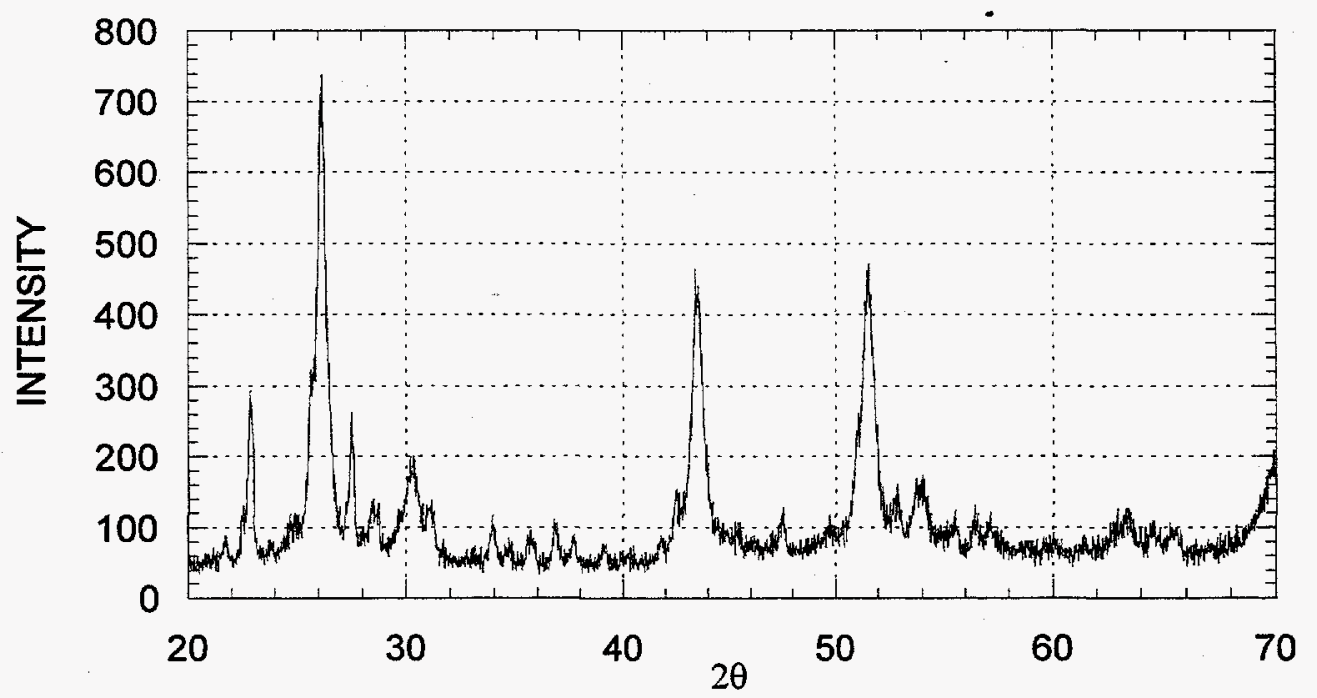

Figure 3. SPC, Mercury and Cyanex 471x: Black Waste Form 
Table 6. X-Ray Diffraction Data for SPC-Hg-Cyanex 471x Waste Form, Cubic Mercuric Sulfide and Orthorhombic Sulfur

\begin{tabular}{|l|l|l|l|l|l|}
\hline \multicolumn{2}{|l|}{ Black Waste Form } & \multicolumn{2}{l|}{ Cubic Mercuric Sulfide } & \multicolumn{2}{l|}{ Orthorhombic Sulfur } \\
\hline d-spacing & Intensity & d-spacing & Intensity & d-spacing & Intensity \\
\hline 3.894 & 34 & & & 3.859 & 100 \\
\hline 3.401 & 100 & 3.378 & 100 & & \\
\hline 3.243 & 31 & & & 3.220 & 50 \\
\hline 2.949 & 28 & 2.926 & 34 & & \\
\hline 2.869 & 19 & & & 2.848 & 23 \\
\hline 2.077 & 65 & 2.068 & 57 & & \\
\hline 1.777 & 65 & 1.764 & 45 & & \\
\hline
\end{tabular}

When sodium sulfide is added to the reaction mixture of mercury and SPC, a reddish brown waste form is the final product. The powder diffraction pattern from that material is shown in Figure 4. The data, shown in Table 7, indicate this material to be a mixture of hexagonal mercuric sulfide or cinnabar [11], and orthorhombic sulfur.

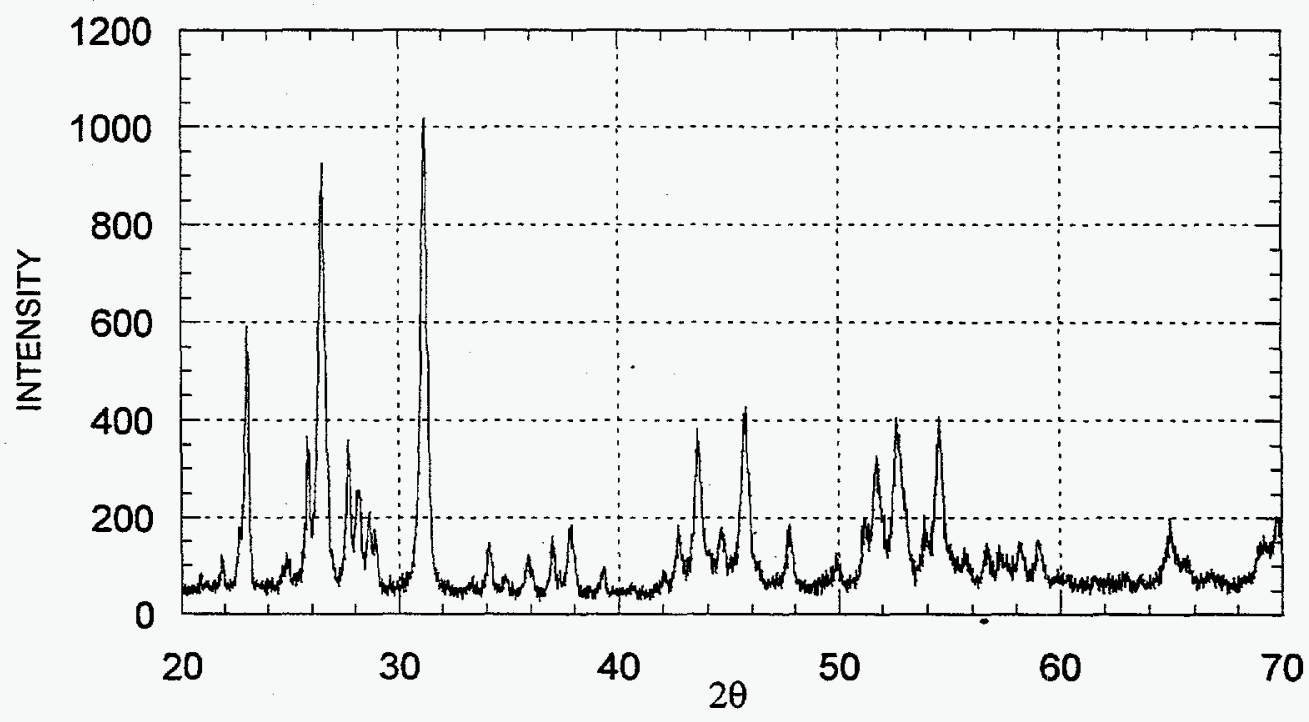

Figure 4. SPC, Mercury and Sodium Sulfide: Red Waste Form 
Table 7. X-Ray Diffraction Data for SPC-Hg- $\mathrm{Na}_{2} \mathrm{~S}$ Waste Form, Cubic Mercuric Sulfide and Orthorhombic Sulfur

\begin{tabular}{|l|l|l|l|l|l|}
\hline \multicolumn{2}{|l|}{ Red Waste Form } & \multicolumn{2}{l|}{$\begin{array}{l}\text { Hexagonal Mercuric } \\
\text { Sulfide }\end{array}$} & \multicolumn{2}{l|}{ Orthorhombic Sulfur } \\
\hline d-spacing & Intensity & d-spacing & Intensity & d-spacing & Intensity \\
\hline 3.844 & 56 & & & 3.859 & 100 \\
\hline 3.360 & 100 & 3.359 & 100 & & \\
\hline 3.213 & 33 & & & 3.220 & 50 \\
\hline 2.857 & 87 & 2.863 & 94 & 2.848 & 23 \\
\hline 2.074 & 41 & 2.074 & 26 & & \\
\hline 1.976 & 31 & 2.068 & 57 & & \\
\hline 1.765 & 35 & 1.764 & 45 & & \\
\hline
\end{tabular}

A sample of stabilized mercuric sulfide was also examined before adding extra SPC and encapsulating it as a waste form. The diffraction pattern of a sample, taken from the reaction mixture of sodium sulfide, mercury and SPC gave a diffraction pattern that was essentially identical to that obtained from the previously examined final waste form, shown in Figure 4. This indicates that the solidification processes do not affect the mercuric sulfide formed during the stabilization step.

From the X-ray diffraction data we can observe two isomorphs of crystalline mercuric sulfide from the reaction of elemental mercury and sulfur in this study. One isomorph of mercuric sulfide, cinnabar, has a hexagonal structure and a bright red color. In this study, waste forms consisting of cinnabar always performed better in the TCLP assays. The other form, metacinnabar, is black and has a cubic structure. When elemental mercury and powdered SPC are mixed, the product is metacinnabar. Adding sodium sulfide results in an exotherm and forces the reaction product to cinnabar. Adding Cyanex $471 x$ also results in an exotherm but the final product is metacinnabar. This change in reaction kinetics, along with the different crystal forms and different leaching behavior suggests that the reaction between mercury and sulfur is susceptible to subtle changes in reaction conditions that dramatically affect the performance and characteristics of the final product. 


\subsection{Mercury Vapor}

One objective of this project was to reduce the volatility of the mercury mixed waste. Therefore, we sought to measure the mercury vapor at various stages of processing. We also measured the mercury vapor given off by the finished waste form. Both sources of mercuiry vapor should be monitored since mercury vapor is a workplace hazard with a low Threshold Limit Value (TLV) level $\left(0.05 \mathrm{mg} / \mathrm{m}^{3}\right)$, which is also the detection limit for the Drager tube. For more sensitive measurements of mercury vapor, more complicated equipment, such as the mercury sniffer must be employed.

During processing we measured mercury vapor concentrations using a Drager tube, which was placed in front of the venting port for the reaction vessel. During the first stage of the reaction, when the elemental mercury was warmed to $\sim 40^{\circ} \mathrm{C} \pm 5^{\circ}$ for about 4 hours, a Drager tube test showed $2 \mathrm{mg} / \mathrm{m}^{3}$ mercury vapors in the atmosphere. Therefore the vessel was placed in a hood and the entrance and venting ports were covered with glass wool to reduce escape of mercury vapor. After the mercuric sulfide is formed, no mercury vapor was detected in the reaction vessel. During the second stage of the process, when

extra SPC is added and the reaction vessel is heated to $135^{\circ} \mathrm{C} \pm 5^{\circ}$ until the mixture melts, no mercury vapor (less than $0.05 \mathrm{mg} / \mathrm{m}^{3}$ ) was detected.

To determine how much mercury vapor was generated from treated mercury, samples of elemental $\mathrm{Hg}$ and waste forms were sealed in 250-ml plastic bottles and the mercury vapor was allowed to reach equilibrium at room temperature. An aliquot $(5 \mathrm{ml})$ of the air from the headspace of the bottle was sampled and measured by direct injection into a gas mixing chamber attached to the mercury cold vapor apparatus of the AA spectrophotometer.

This method was calibrated by injecting into $260 \mathrm{cc}$ septum topped bottles, measured quantities of $100 \mathrm{ppb}$ mercury standard solution and stannous chloride. The reaction between the two reagents quantitatively generated $\mathrm{Hg}$ vapor. Five $\mathrm{ml}$ of this vapor were withdrawn by syringe and injected into the mixing chamber on the Cold Vapor apparatus on the AA. The calibration obtained in this way is shown in Figure 5.

Equilibrium mercury vapor concentrations were characteristic of the different materials analyzed. As shown in Table 8 , the $\mathrm{Hg}$ vapor concentration over the elemental mercury was about $100 \mathrm{ug} / \mathrm{L}$. This was measured periodically over several weeks and was reproducible. Treated mercury had much lower vapor concentrations, typically at least an order of magnitude lower than elemental mercury. Waste forms produced with $\mathrm{Na}_{2} \mathrm{~S}$ on average had lower vapor concentrations than the other treated wastes but this was a function of age of the material. This is illustrated in Figure 6 which shows how the vapor concentration changed over time. Based on the behavior of other samples, we do not believe there was loss of $\mathrm{Hg}$ from the bottle, rather that the $\mathrm{S}$ and $\mathrm{Hg}$ continued to react, slowly moving toward the $\mathrm{HgS}$ form with its lower vapor concentrations. 


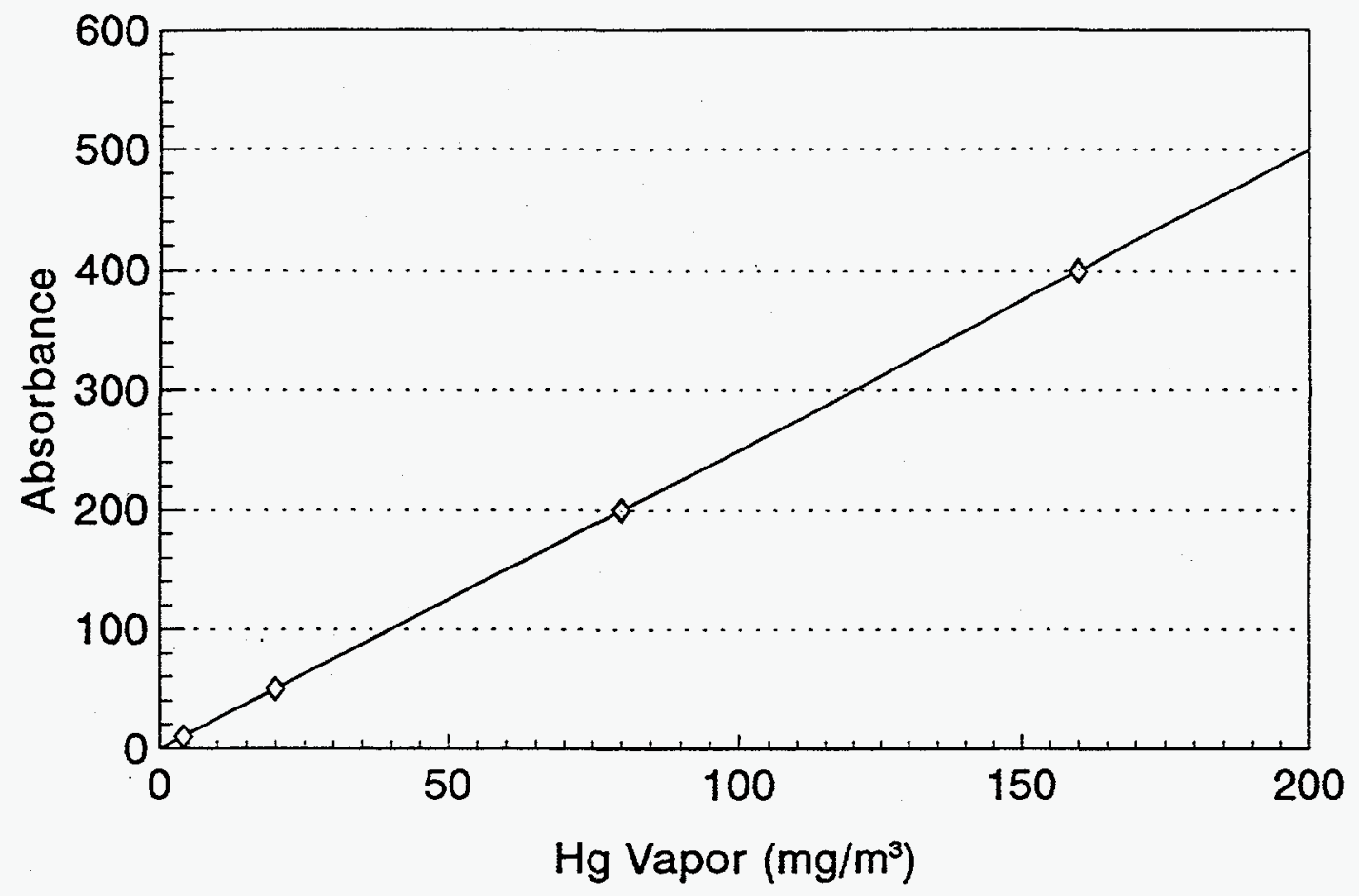

Figure 5. Calibration plot of $\mathrm{Hg}$ vapor generated by reduction of aqueous $\mathrm{Hg}$ with Stannous Chloride. The vapor concentrations observed by the adaptation of the AA cold vapor method to vapor samples taken by syringe, gave a linear relationship.

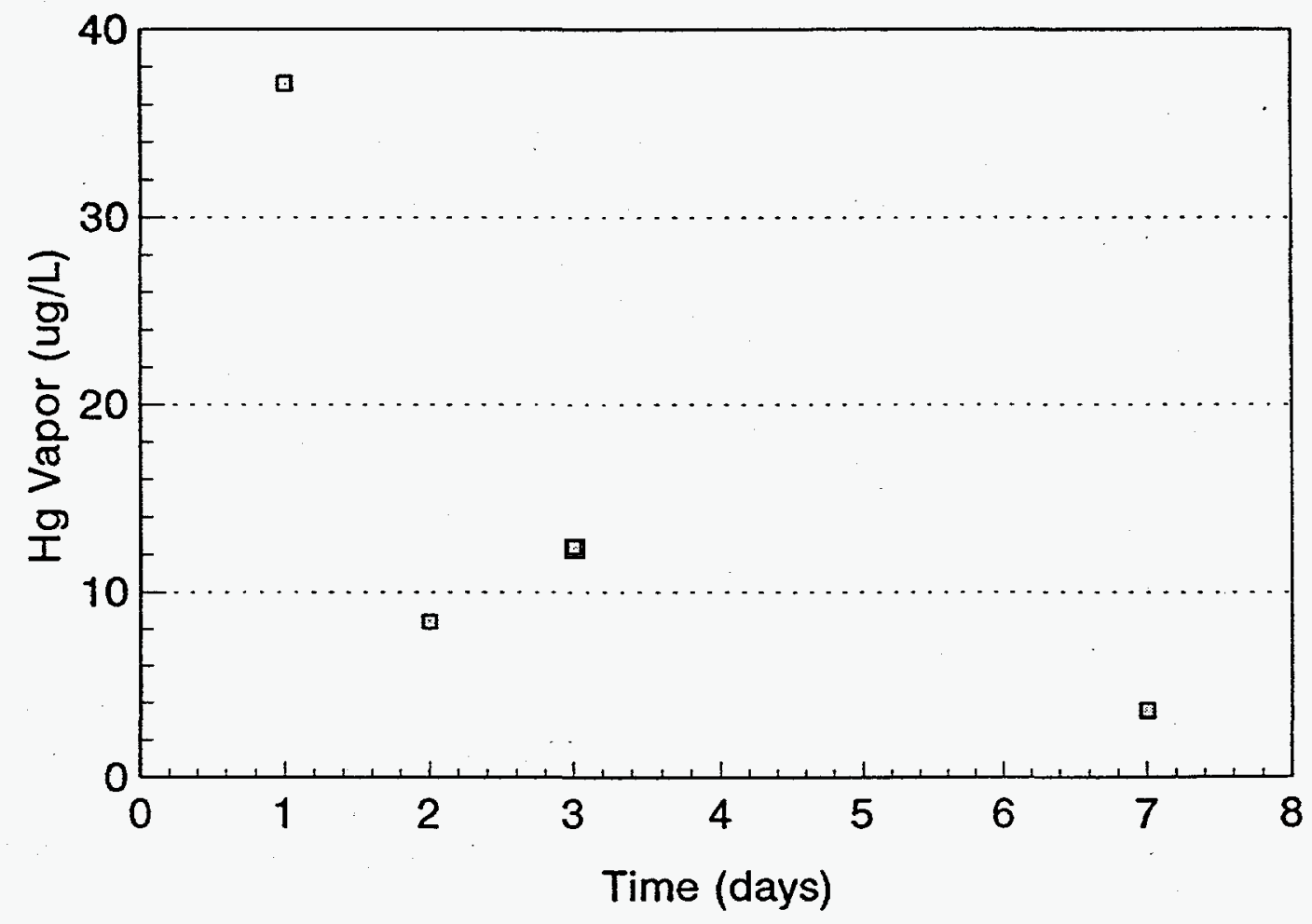

Figure 6. Concentration of $\mathrm{Hg}$ vapor as a function of time, in a bottle containing $\mathrm{Hg}$ processed in SPC. The vapor concentration decreases over a period of a week. 
Table 8. Hg Vapor concentrations in Bottles Containing Various Hg Wastes

\begin{tabular}{|c|c|c|}
\hline Sample & Absorbance & $\mathrm{Hg}$ Vapor ug/L \\
\hline Elemental Hg & 243,273 & 97,109 \\
\hline $\mathrm{Hg}+\mathrm{SPC}+\mathrm{Cyanex} 471$ & 8,14 & $3.2,5.6$ \\
\hline Reagent HgS (red) & 3 & 1.2 \\
\hline $\mathrm{Hg}+\mathrm{SPC}$ & 13,16 & $5.2,6.4$ \\
\hline $\mathrm{Hg}+\mathrm{SPC}+\mathrm{Cyanex} 471$ for TCLP III & 37,50 & 15,20 \\
\hline $\mathrm{Hg}+\mathrm{SPC}+\mathrm{Na}_{2} \mathrm{~S}$ pellets for TCLP II & 5,9 & $2.0,3.6$ \\
\hline $\mathrm{Hg}+\mathrm{SPC}$ pellets for TCLP I & 82,98 & 33,39 \\
\hline $\mathrm{Hg}+\mathrm{SPC}+\mathrm{Na}_{2} \mathrm{~S}$ (New) & 21,28 & $8.4,11.2$ \\
\hline
\end{tabular}

\subsection{Processing BNL's Inventory of Mixed Mercury Waste}

The BNL inventory of mixed mercury waste is shown in Table 9. The mercury was treated identically to that of the uncontaminated mercury using sodium sulfide nonahydrate additive. The material behaved similarly to other mercury batches. However during the second step of the process, when the mercuric sulfide was mixed with excess SPC and

Table 9. BNL Inventory of Mixed Mercury Waste

\begin{tabular}{|l|c|c|c|}
\hline \multicolumn{2}{|l|}{ Radionuclide Contaminant } & Activity & Amount of Mercury Metal \\
\hline Germanium & ${ }^{68} \mathrm{C}$ & $1 \mu \mathrm{Ci}$ & $2.2 \mathrm{~kg}$ \\
\hline Carbon & ${ }^{14} \mathrm{C}$ & $25 \mu \mathrm{Ci}$ & less than $0.2 \mathrm{~kg}$ \\
\hline Cesium & ${ }^{137} \mathrm{Cs}$ & $1 \times 10^{-2} \mu \mathrm{Ci}$ & $16.1 \mathrm{~kg}$ \\
\hline Tritium & ${ }^{3} \mathrm{H}$ & $1 \mathrm{mCi}$ & $6 \mathrm{~kg}$ \\
\hline
\end{tabular}

shaken, the vent holes on the top of the reaction vessel frequently clogged. This was caused by molten SPC splashing into these vent holes and solidifying. We had to clear these vent holes to pour out the molten waste material, and prevent a hazardous pressure build up since water vapor and other gases were released during this stage of the process. This problem was partially mitigated by insulating the top of the reaction vessel and carefully watching the vessel and clearing any clogged vents immediately. After 
processing, the molten mixtures were poured into 1 gallon paint cans and cooled. A total of five batches of waste forms, (each consisting of about three paint cans) were produced for disposal. TCLP test specimens were taken from each batch and a TCLP test was conducted on a $50 \mathrm{~g}$ sample ( $10 \mathrm{~g}$ from each of five batches). This resulted in a TCLP concentration of $50 \mathrm{ppb}$, well below the EPA limit of $200 \mathrm{ppb}$. A 100 gram sample, made up of 20 grams from each batch was given to the Waste Management Division for an independent assay to verify if the waste would pass TCLP and thus, be acceptable as radioactive waste.

\subsection{SUMMARY AND CONCLUSIONS}

A unique process to stabilize and solidify mixed waste mercury was successfully developed and tested using bench-scale processing equipment. The process:

- $\quad$ reduces mercury solubility to enable compliance with EPA TCLP criteria

- lowers mercury vapor pressure during processing and in the final product

- $\quad$ eliminates dispersibility of the stabilized product

- reduces leachability of radioactive constituents

With support from the Mixed Waste Focus Area Quick Win Program, the entire BNL inventory of mixed waste elemental mercury was successfully treated, allowing disposal of the resulting waste forms as conventional low-level radioactive waste.

The method involves a simple two stage process in which the mercury is first stabilized with powdered SPC and additives to form mercuric sulfide and is mixed with additional SPC then heated to form a solid monolithic waste form. The impact of additives on reaction kinetics, leachability and mercury vapor concentration were determined. The optimal form of mercuric sulfide (i.e., hexagonal) was confirmed by $\mathrm{X}$-ray diffraction. Compliance with EPA TCLP requirements was confirmed. Final waste form products produced from actual BNL mixed waste mercury resulted in a mercury concentration of 50 $\mathrm{ppb}$., significantly lower than the EPA allowable concentration of $200 \mathrm{ppb}$. This process provides a cost-effective solution for the treatment of mixed waste mercury currently stored throughout the DOE complex (e.g., Savannah River Site, Oak Ridge National Laboratory). Based on successful results of this bench scale study, additional work is needed to examine scale-up feasibility, application to other mercury waste streams (e.g., mercury contaminated soils and debris and mercury salts) and to characterize fully the performance and durability of the final waste forms. 


\subsection{REFERENCES}

1. Gorin, A.H., J. H. Leckey and L.E. Nulf, "Final Disposal Options for Mercury/Uranium Mixed Wastes From The Oak Ridge Reservation", Y/DZ-1106, August 1994

2. Kalb, P.D., Heiser, J.H., and Colombo, P., "Modified Sulfur Cement Encapsulation of Mixed Waste Contaminated Incinerator Fly Ash," Waste Management, Volume 11, No. 3, pp. 147-153, Pergamon Press, 1991.

3. Kalb, P.D., Heiser, J.H., Pietrzak, R., and Colombo, P., "Durability of Incinerator Ash Waste Encapsulated in Modified Sulfur Cement," Presented at the 1991 Incineration Conference: Thermal Treatment of Radioactive, Hazardous, Chemical, Mixed, and Medical Wastes," Knoxville, TN, May 13-17, 1991.

4. Lin, S-L., Lai, J. S., Chian, S. K. "Modifications of Sulfur Polymer Cement (SPC) Stabilization and Solidification (S/S) Process," Waste Management, Volume 15, No. 5/6, pp. 441-447, Pergamon Press, 1995.

5. Colombo, P., Kalb, P.D., Heiser, J. H. "Process for the Encapsulation and Stabilization of Radioactive, Hazardous and Mixed Wastes." U.S. Patent 5,678,234, October 14, 1997.

6. US EPA, "Toxicity Characteristic Leaching Procedure (TCLP)", 40 CFR 261, Appendix II, U.S. Environmental Protection Agency, Washington DC, September 19, 1994.

7. Singh, R.; Tandn, S. N. "Extraction and Separation of mercury (II) Using Triisobutyl Phosphine Sulfide (TIPS/Cyanex 471x) as an Extractant and Its Application to Industrial Effluent." Talanta, Volume 44, No. 5, pp 843-848.

8. Moser, H.C. and Voigt, A. F. J. Am. Chem. Soc. 1957, 79, 1837

9. Swanson, H. E., Cook, M. I. Isaacs, T. Evans, E. H. "Standard X-Ray Diffraction Patterns." Circular 539, Volume 9, pp 54-56.

10. Sliva, P., Peng, Y. B., Peeler, D. K., Bunnell, L. R.; Turner, P. J.; Martin, P. F.; Feng, X. "Sulfur Polymer Cement as A Low-Level Waste Glass Matrix Encapsulant." PNNL-10947, Pacific Northwest National Laboratory. Richland, WA. January 1996.

11. Swanson, H. E., Fuyat, R. K., Ugrinic, G. M. "Standard X-Ray Diffraction Patterns." Circular 539, Volume 4, pp 17-22. 